\title{
PATOLOGY
}

UDC 616-092.11:612.67

\section{Ageing Acceleration and Disease Onset: Ontogenetic Specificity of Pathogenetic Mechanisms}

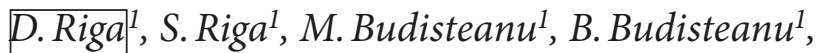 \\ V.Dionisie ${ }^{1}$, V. V.Scripnic ${ }^{2}$ \\ 1 "Prof. Dr. Alexandru Obregia" Clinical Hospital of Psychiatry, \\ 10-12, Berceni av., Sector 4, 041914, Bucharest, Romania \\ 2 International Free University of Moldova, \\ 52, Vlaicu Pârcălab str., MD-2012, Chisinau, Republic of Moldova
}

For citation: Riga D., Riga S., Budisteanu M., Budisteanu B., Dionisie V., Scripnic V.V. Ageing Acceleration and Disease Onset: Ontogenetic Specificity of Pathogenetic Mechanisms. Vestnik of Saint Petersburg University. Medicine, 2019, vol. 14, issue 2, pp. 105-122.

https://doi.org/10.21638/spbu11.2019.203

The article which unfortunately happened to be the last poshumous paper published by recently deseased Prof. Habil. Dan Riga, MD, PhD, DHc, is devoted to the problem of imperfection and vulnerability of the natural genetically determined adaptation mechanisms available to human being. All defensive mechanisms encoded in human reactivity are principally imperfect and have to cause secondary harm. It means that the very defence is pathogenic, especially in chronic situations when the natural cost of adaptation increases to unbearably high level. That is central paradigm of the whole science of Pathophysiology. The imperfection and secondary pathogenicity of natural defence (autopathokinesis) was emphasized earlier, since first coined by August Weismann, for example in works published by L. P. Churilov. This article analyses the basic aspects of health and disease under the aforementioned bias, with original interpretation of the role of vulnerability and imperfection of human defensive mechanisms in chronic repeated stress and within the continuum of physiologic and pathological senescence. The principle is illustrated by several examples from the general pathology of typical pathological processes and with the correlations to most important geriatric syndromes and diseases. According the statements of the authors, the human being has an ontogenetic route, from childhood and youth health, through adulthood, towards old age (senescence) and related multiple pathology (including dementia). Human vulnerability is extremely complex and manifests at different levels: macromolecular, sub-cellular, cellular, tissual, of organs, of biological system, with additional specific traits for the central nervous system. Slowly, throughout individual ontogenesis, closely related to vulnerability, an etiopathogenic cascade (tetrad)

(c) Санкт-Петербургский государственный университет, 2019 
develops: it is entropic, of structures disorganisation and disturbance of their functioning: distress wear-and-tear "ageing" poly-pathology. Its dynamics is self-sustained, aggravated, and rendered more complex by vicious patho-physiological multiplication circuits.

Keywords: ontogenesis, sanogenesis, distress, oxidative stress, wear, ectropic, brain volatility, optoptosis, telomere, telomerase, molecular chaperones, heat-shoch proteins (HSB), etiopathogenic entropy cascade, stressful lifestyles.

\section{The Human being: from health to disease}

Health (evaluated as the state of normality) and sanogenesis (the process of constructing, maintaining, and developing health) are completely antagonistic to disease (defined as the state of abnormality) and pathogenesis/morbidity genesis (the process of reducing, depreciating, destructing health, therefore a reverse process of sanogenesis, meaning the "construction," aggravation, and complication of the condition).

Sanogenesis $\rightarrow$ health and pathogenesis $\rightarrow$ condition are fundamentally different dynamic processes, both in essence and especially in their end (state). Related to the human bio-system, health is the result of organisation, training, and increased efficiency, as opposed to disease which is the consequence of disorganisation, destabilisation, and permanent decreasing efficiency.

Sanogenesis, morbidity genesis, and therapy ("the fight" against pathogenesis) are pairs of dynamic processes due to multiple causes, with divergent ends in the states of health, disease, and therapy.

The three different types of processes $\rightarrow$ states are the result of functioning ("flowing") over time of three different "cascades," according to the common amplification in progression. They manifest in divergent binomials and, structurally, they are equally different and antagonistic.

The "play" of the individual's ontogenesis develops in four "acts," by progressively and orderly going through a "serial of scenes" [33]:

- "act" 1, of diminishing health $\rightarrow$ very good health (optimal) $\rightarrow$ good (sub-optimal) $\rightarrow$ medium (frequent) $\rightarrow$ oscillating (fragile) $\rightarrow$

- "act" 2, of the pair's coexistence: sub-health + chronic pre-disease ("anteroom" of diseases) - sub-health (frail health) $\rightarrow$ metabolic pre-pathology, ante-subclinical (oxidative health, pro-inflammation) $\rightarrow$

- "act" 3, of disease "construction" $\rightarrow$ sub-clinical medicine (chronic silent pathology: debut $\rightarrow$ subclinical constitution) $\rightarrow$ clinical medicine (clinical debut $\rightarrow$ extension/aggravation $\rightarrow$ poly-pathology $\rightarrow$ complications) $\rightarrow$

- "act" 4, of chronic simultaneity: disease + therapy (mono-therapy $\rightarrow$ increased dosage $\rightarrow$ poly-therapy).

All human life stages (cycles) are negatively affected by the simultaneity of the antiphysiological and time-dependent "cascade", which is chronologically initiated by distress and later on extended and aggravated by the same distress (in turning it chronic and acute).

It is the entropic "cascade"/tetrad distress $\rightarrow$ fatigue $\rightarrow$ ageing $\rightarrow$ poly-pathology [31]. Moreover, it is essential to ascertain three characteristic features of the "cascade", which we can rightly call the ontogenesis "cascade": 
- everything "flows" (progresses) and accumulates over time: distress, fatigue, ageing, poly-pathology;

- the cascade disturbs the individual as a bi-psycho-social system (all levels of organisation, i. e., structural, functional, informational are affected);

- the entire cascade "increases dramatism" in the individual's ontogenesis "play," with more and more negative intensities, duration, and consequences.

The human being (a hierarchically-built and extremely complex bio-system, with structural, functional, energetic, and informational specificity/properties, with a socially multiple and over-functionality of the person, from birth to death (ontogenesis, cycles of life), enters - conscientiously and/or unconscientiously - one of the two opposite, antagonistic, routes:

$\rightarrow$ the health "route" - adaptation and resistance, conscientisation, and "training" of health, the anti-entropic (ectopic) "route" of sanogenesis and longevity, of (self)development, progress, and evolution; or

$\rightarrow$ the "chronic disease" route - mal- / dis-adaptation and becoming vulnerable, risks, and unbalance, the entropic "route", of disorganisation, pathogenesis, and mortality, of regress and involution.

Under these circumstances, the disorganising entropic "cascade"/ tetrad, etio $\rightarrow$ pathogenic: distress $\rightarrow$ fatigue $\rightarrow$ ageing $\rightarrow$ poly-pathology, becomes a new paradigm in bio-medicine, public health, anti-ageing medicine, longevity sciences, and stress medicine [31].

The results of applying the scales / "weighing" the effects $\rightarrow$ consequences $(+) /(-)$ creates an "accountability" with two antagonistic polarities:

- GREAT numerator / SMALL denominator $=$ positive result $(+)$, greater than one unit = health and longevity;

- SMALL numerator / GREAT denominator=negative result (-), less than one unit $=($ chronic/acute $)$ pathology and premature mortality.

\section{Human vulnerability - a key factor in reception, propagation, aggravation, and multiplication of diseases}

Vulnerability (Lat. vulnerabilis = vulnerable, from vulnus, - eris = wound), the ensemble of inherited (genetic) factors or acquired ones (in the interaction with external environment), which predispose to the onset and development of a condition, represents a fundamental concept in the etiopathogenic interpretation of biomedical phenomena [10].

Biological vulnerability $(\mathrm{BV})$ is structured in compliance with the general biological organisation plan: from macromolecular level, sub-cellular, cellular to the tissual, organ, and system. In addition, in the human being, BV is the premises and component of neuropsychic vulnerability [32].

Neuropsychic vulnerability (NPV) highlights valences of the human being's becoming vulnerable, as the human being is a bio-psycho-social entity.

Therefore, H. Selye underlines the importance of each individual's life philosophy in the adaptive efforts they make throughout ontogenesis: The current humanity's greatest challenge is to find a philosophy of life, a code of conduct, that would provide for a good ori- 
entation, not to avoid stress (which is impossible), but to overcome it, to achieve the state of health, long life, and happiness [41-43].

The term of vulnerability is close to the term of 'imperfection' used by L. P. Churilov to designate vulnerable and costly character of the natural defensive mechanisms encoded in human reactivity and their inherent ability to cause secondary harm with impossibility of "pure" defence.

Vulnerability is directly linked - from the phenomenological, causal, processual (effect) point of view - to an essential "target" in the stress medicine. Vulnerability is the "anteroom" of stress and, according to the vulnerability/stress (eu-/di-stress) model, ensures the dichotomy sanogenesis/pathogenesis [28].

\section{Vulnerability - the "anteroom" of distress in the human being's sanogenesis $\rightarrow$ pathogenesis $\rightarrow$ therapy}

\subsection{Biological vulnerability at the macromolecular level}

From genetic viewpoint, biological vulnerability (VB) manifests by various resistance/frailty according to the organ or intracellular compartment and turns into genetic pathology via three groups of processes: modification of genes (mutations), loss of genes and disturbance of telomere/telomerase system.

Nuclear DNA vulnerability and the disabling consequences of genetic BV $\rightarrow$ under normal circumstances, accompany the synthesis of new proteins, facilitating their plication, namely, acquisition of a three-dimensional structure, a configuration that is necessary to become functional;

- under unfavourable circumstances, distressing and pathological, proteins lose their normal plication (spatial structure) forming intracellular aggregates which disturb cell activity, determining thus their death;

- under heat-shock or any other such distress manifested at cell level, chaperone proteins:

- prevent aggregation;

- oppose to and even stop the process of aggregation, in case such process has already been initiated;

- and, as a third mechanism, activates the proteolytic degradation of proteins whose aggregation cannot be stopped or of proteins already aggregated.

Mitochondrial DNA vulnerability results from its characteristic: is a closed circular macromolecule formed of 16,568 pairs of nucleotides codifying 37 mitochondrial genes. Mitochondrial DNA has a higher mutating rate (hence, it is more vulnerable) than nuclear DNA (nuclear genome).

Mitochondrial DNA mutations - from post-mitotic tissues (brain, heart, skeletal muscles, kidneys, endocrine system) cause in human degenerative neuromuscular diseases, with a significant neuropsychic disability and accelerated, pathological ageing. The metabolicmitochondrial bioenergetics is disturbed, with consequences in progressive alteration of structures - cellular functions and, eventually, system or individual functions [49].

Telomere/telomerase system owing to normal/disturbed functionality tilts the balance: either towards protection or towards vulnerability - frailty. Telomeres are specialised 
structures made up of a repetitive nucleic nitrogenous bases string (200-1,500), rich in guanine, located at the extremity of each chromosome branch (opposite to the centromere). The telomere, in humans the TTAGGG hexamer, added under telomerase action (enzyme, ribonucleic protein) ensures integrity of chromosomes and prevents them from fusing.

During repeated cellular divisions throughout ontogenesis, a gradual decrease of telomere's length takes place, which thus is in relation with oxidative stress, biological wearand-tear, ageing, and cell death. This happens because telomerase activity, the enzyme counterattacking the telomeres shortening by their re-elongation, is strong only in immortal cells and almost absent in other cell types [54].

Chaperone ("molecular chaperones") proteins constitute another area of macromolecular vulnerability. They are a very non-homogeneous group made up from approximately 200 proteins, most of which belong to thermal stress (heat-shock) protein (HSP) super family. Normally representing 1-2\% of the total cell content, chaperones are universally synthesised by cells as a response to distress of which one is increased temperature.

Their role in macromolecular vulnerability is crucial [48] as:

- under normal circumstances, accompany the synthesis of new proteins, facilitating their plication, namely, acquisition of a three-dimensional structure, a configuration that is necessary to become functional;

- under unfavourable circumstances, distressing and pathological, proteins lose their normal plication (spatial structure) forming intracellular aggregates which disturb cell activity, determining thus their death;

- under heat-shock or any other such distress manifested at cell level, chaperone proteins:

- prevent aggregation;

- oppose to and even stop the process of aggregation, in case such process has already been initiated;

- and, as a third mechanism, activates the proteolytic degradation of proteins whose aggregation cannot be stopped or of proteins already aggregated.

By protecting homeostasis at the macromolecular level, as most of chaperones are found and activate in toxic and distressing situations, they oppose to the macro-molecular-sub-cellular-cellular vulnerability; conversely, the increase of BV determines a decrease in their efficiency.

\subsection{Biological vulnerability at sub-cellular level}

In the neuron, BV at sub-cellular level is a consequence of its characteristics. The neuron is a fixed post-mitotic cell (in the Gt stage) with long life, has the greatest structural-functional redundancy and acquired the most developed ultra-differentiation (morphological structuring) and the highest ultra-specialisation (functional activity), which determines the nervous system to work (from the energetic and informational) at the lowest entropy level (from among all the apparatuses, organs, and cells of the body) [24].

The neurometabolic support $\rightarrow$ sub-cellular of these properties is given in neuron as obviously compared to other types of cells - by [25]:

- the most intense proteinic synthesis (polyribosomes, rough endoplasmic reticulum, tigroid bodies); 
- ensured by (therefore, dependent, vulnerable) energetic metabolism (mitochondria) the most intense and with the highest output / cell (neuron); and

- recycled via the most efficient, active, and well-represented from a quantitative point of view sub-cellular recycling system (primary, secondary, and tertiary lysosomes).

In terms of their relation to BV - sub-cellular level, the neuron features (performances) from neurometabolic and sub-cellular viewpoint can be also grouped in the metabolism dynamics: metabolism (functional - structural $)=$ anabolism $($ synthesis, construction) (1) $\varnothing$ (3) catabolism (destruction),

Where $\varnothing$ represents (2) energetic metabolism, which provides biochemical energy (ATP) whereby the two antagonistic processes are continuously fed: (1)/3.

Oxidative stress is triggered by divergent disturbance: strains/resources, namely the double lack of balance between oxidising aggression - increasing and anti-oxidising defence - decreasing $[12 ; 13 ; 16]$.

Thus, the stress/vulnerability binomial, analysed in the neuron at sub-cellular level reveals in etio $\rightarrow$ pathogenic relation the following [29]:

- the oxidative stress will be the more toxic as:

- the greater the aggression (exo-/endogenic) by free radicals, pro-oxidants, per-, auto-, co-oxidation;

- the smaller the protection and defence (exo-/endogenic) supported by quenchers, scavengers, antioxidants;

- vulnerability (mainly the one accumulated over time by wear-and-tear $\rightarrow$ will be greater as:

- the energetic metabolism drops due to mitochondrial loss and anabolism will be reduced by decreasing RNA synthesis $\rightarrow$ proteins, enzymes $\rightarrow$ sub-cellular organelles (sub-cellular regeneration);

- catabolism will overcome anabolism and will become inefficient in sub-cellular recycling - cleansing, which translates in progressive accumulation and nonelimination of sub-cellular waste.

Conversely, the convergent double re-balancing of ratios (balances, binomials): oxidative stress /anti oxidising protection and defence; and vulnerability-frailty/resistancevitality, is done in the pathogenic $\leftrightarrow$ therapeutic relation [30].

The accumulation over time of oxidative stress increases BV in the neuron, from the metabolic level to the sub-cellular and cellular one:

- at neurometabolic level, by the accumulation of "metabolic waste" - excess of: free radicals, intracellular calcium, cross-links, disulphuric groups (oxidised), lipid peroxides, polymerisations (dolichols), insoluble (in water) proteins;

- at sub-cellular level: mitochondrial overload with calcium, mitochondrial waste and altered mitochondria, accumulation of "sub-cellular waste" - lipofuscin pigments (wear-and-tear pigments, tertiary lysosomes, old lysosomes - resulted from lysosomal digestion mainly of altered mitochondria) and ceroid pigments $[1 ; 17]$;

- at neuronal level: conglomeration, structural piling up of lipofuscin pigments (under normal circumstances) and ceroid one (under pathological circumstanc- 
es) - representing neuro-psycho-biological markers for the (oxidative) stress and sub-cellular - cellular vulnerability.

\subsection{Biological vulnerability at the cellular level}

In terms of quantity, the cellular level is controlled via two normal physiological processes which are opposed: cell division (mitosis) and apoptosis (programmed cell death).

Apoptosis (in Ancient Greek, "apoptein" - to throw out or by joining two words "apo" - from, and "ptosis" - fall; a word used by Homer in the Iliad, meaning fall of the leaves from trees in autumn and the phenomenon intuited and postulated by C. Vogt in 1842) represents the normal cell death, isolated and programmed, thus closing the normal cell cycle and creating physiological conditions for cell replacement [22]. Owing to these characteristics, apoptosis becomes a key factor in tissual homeostasis, in embryogenesis, and morphogenesis and operates as a "referee" of growth, differentiation, and regeneration $[14 ; 32]$.

Apoptosis, as a physiological process at the cell level, is inscribed in the cellular genetic programme, is carried out with energy consumption, and has its own biochemical stages and mechanisms of development, without being accompanied by inflammatory processes and tissular reactions.

Apoptosis is fundamentally distinct from necrosis (in Ancient Greek, "nekros" death, "nekrosis" - mortification), which represents the pathological cell death. A consequence of the intervention of some external noxious factors - necrotic death is not controlled genetically and is always accompanied by inflammatory processes which leave cell remains and waste together with tissual scars.

Apoptosis disorder is encountered in various pathological situations and manifests in both directions:

- triggers a premature and accelerated apoptosis in wear-and-tear, ageing, and neuro-degenerative conditions;

- inhibits apoptosis in tumour processes.

The decrease of vulnerability at the cell level, simultaneous with the increase of biological resistance can be achieved by modulating apoptosis and avoiding necrosis.

Apoptosis modulation plays an important role. It is carried out via inducing factors (pro-apoptotic) and inhibiting apoptotic ones (anti-apoptotic). The molecular chaperones' anti-apoptotic effects are known (notably, HSP70 and HSP90).

The intensity of the noxious/pathological agent determines cell behaviour: towards apoptosis or towards necrosis. From this perspective, apoptosis becomes a mechanism of defence and adaptation. Thus, ionising radiations in small moderate doses induce apoptosis in normal tissues, playing the role of a trigger of apoptosis by means of minimal cell DNA alterations, which, if they cannot be repaired, activate the p53 gene (pro-apoptotic). In large and very large doses, ionising radiations produce circumscribed or extended cellular/tissular necrosis. And so does the aggression by hypoxia. It can induce apoptosis or trigger necrosis. Mild to moderate hypoxia, occurring in areas adjacent to necrosis, becomes an efficient inductor of apoptosis, by acting on the p53 gene. Severe hypoxia/ischemia determines necrosis, which in the CNS has certain selectivity. 
Avoiding cellular/tissual necrosis resides firstly in avoiding physical trauma of known pathogenic agents: physical and chemical fumes, pollution, hypoxia, and ischemia, viral and bacterial infections. The growth of general biological, immune, and neuropsychic resistance diminishes the vulnerability to necrosis when aggression cannot be avoided.

\subsection{Selective vulnerability of the brain}

The current life and society's negative consequences, the external aggressions and noxious manifestations of the environment most frequently determine, at the human body's level [26]:

- psycho-neuro-biological distress in the most diverse forms, should we take into account the variety, intensity, and duration of the noxious stressing agents (distressors);

- hypoxic/ischemic stress, which can be global/regional, transient/persistent, circulating stress (the decrease while growing older of the Cerebral Blood Flow $\mathrm{CBF}$;

- oxidative stress, followed by a cascade of negative events:

- physical, chemical, biological, psycho-social, professional, informational, communicational, competitive;

- over-acute, acute, chronic, post-chronic distress;

- simultaneous, multiple, prolonged distress, the actual accumulation of distress types over long periods of time.

The evolution in time of ontogenic stages induces the decrease of structural redundancy and of functional reserve at the same time with accumulation of errors and defects that can no longer be compensated, eliminated, or alleviated.

Thus, the fact that the human body becomes more fragile/its resistance diminishes determines the accentuation/growth of BV and develops along with it.

With respect to the CNS - Central Nervous System, BV has a major and extremely important specific trait: it is a selective vulnerability. This is due to fact that the brain is the most non-homogeneous and heterogeneous of human body organs and has the most complex and diversified structure and functionality. Selective vulnerability means that faced with the same aggression/disease, which is global, the brain reacts differently and selectively; this means that only certain regions/areas are affected, where biochemicalstructural modifications occur [2].

\subsection{Selective vulnerability of the CNS in global hypoxia/ischemia}

The aggression by global hypoxia/ischemia determines at the CNS level the following pattern of selective vulnerability $[19 ; 46]$ :

- at the area level: the most distal (terminal) capillary territories, the layer of pyramidal cells from:

- hippocampus, the layer of Purkinje cells in cerebellum, the cortical layers III, IV, and V; 
- within some apparently homogeneous neuronal populations, such as the hippocampus pyramidal cells layer, certain neuronal sectors are more vulnerable, namely CA1 area (Sommer sector) as compared to CA3 resistant area;

- at the cellular level, neurons are more vulnerable to diverse degrees of hypoxia/ ischemia than the oligodendroglia, and the latter are more vulnerable than astrocytes.

It is important to clarify the mechanisms that make certain regions of CNS to be more vulnerable, and others to be more resistant to transient/persistent global hypoxia situations.

One of the mechanisms would be the release of glutamate, ubiquitous neurotransmitter, able to determine in excess neuronal necrosis via hyperexcitation (excitotoxic neuronal death). Thus, transient global cerebral ischemia induces the release of glutamate in the extracellular space [3]. In hippocampus, sensitive to this type of aggression, exciting receptors for glutamate are in large quantities in CA1 (Sommer sector) area, which is more vulnerably and which contains, still in significant quantities, mainly a certain subtype of glutamate receptor, namely NMDA receptors ( $\mathrm{N}$-methyl-D-aspartate).

Another mechanism that would explain vulnerability to this type of hypoxia is selective loss [39] of GABAergic neurons (Gamma-Amino Butyric Acid).

Another modality of action involves knowledge of diverse regions' chemical-biochemical special traits in CNS. Thus, we can understand the pale globe (globus pallidus) and the reticulate part of the black substance (substantia nigra, pars reticulata) selective vulnerability (necrosis) to monoxide $(\mathrm{CO})$ intoxication. These two brain regions are the richest in iron $(\mathrm{Fe})$, and the $\mathrm{CO}$ molecule has an extreme affinity to $\mathrm{Fe}$ in the cytochrome heme [20].

\subsection{Selective vulnerability of CNS in distress}

The distress phenomenon - psycho-social and biological, acute and chronic a profoundly negative feature of contemporary life, includes the development of three subsequent processes [33]:

- firstly - the aggression to the organism by stressing factors (stressors), which undergo an ongoing process of growth, diversification, and becoming permanent;

- secondly - the adaptive response of the organism - GAS - the General Adaptation Syndrome, with its three stages - the alarm, resistance, and weariness stages. The GAS often turns into a maladaptive or pathological stress-dependent response also as a consequence of the BV constant growth alongside with ontogenesis development; and

- thirdly - the intensely and chronically accelerated and accumulated brain and organism wear-and-tear, meaning premature ageing. Chronic wear-and-tear represents the progressive neuropsychic and biological incapacitation; it results in diminished adaptation, vitality, and resistance of the organism and is a consequence of over time accumulation of stressful events in one's life and of lesions caused by stress. 
Due to the increase of biological vulnerability, throughout ontogenesis, ageing $\leftrightarrow$ distress binomial acquires new features [11] by way of the:

- modifications induced by biological senescence (structural and functional), followed by psychic modifications (cognitive and emotional), which demodulates the stress-aged organism interrelations;

- low resources, resistance, and redundancy (biological and psychic), which determine increased vulnerabilities (structural-functional and cognitive-emotional) to aggressions and distress. The interrelation was also demonstrated through experiments: glucocorticoid receptors in rat brain decrease with age [37], and suprarenal glands also manifest the same tendency, of decreased sensitivity to ACTH in aged animals; this tendency can be compensated by higher basal levels of ACTH [47]; thus, aged rats display a higher level of vulnerability to stress than younger ones as they are less adapted to stress [23];

- low adaptive possibilities (biological and psychic), which imply growth of the mal-adaptation frequency and intensity, accompanied by accentuation and aggravation of prior stress-dependent pathology (of adaptation-related conditions), which occurred mainly during adult stage [15];

- the decrease of independence from stressors, environment, and community paralleled by simultaneous increase of dependence (and of the fear of dependence) on the environment, family, and society.

The complexity of life and the diversity of stressors determine in many individuals the onset of the $\mathbf{C}$ type personality (synthesised by chronic stress and high levels of cortisol). Most often, this happens because modern life distressors do not allow a normal response, be it a simple one, to stress (mainly the "fight or run" emergency response), with the manifestation of A and B type personality.

By making the stressors permanent, the response to stress process - GAS becomes chronic and the increasingly high values of stress hormones, mainly adrenalin and cortisol, determine body tissues modifications and lesions, brain included. Consequently, BV to stress is mainly the result of the hyperadrenergic state and of a high chronic level of cortisol. In conclusion, prolonged chronic stress, combined, over layered, and continuous, determines the chronic production of cortisol maintaining such level permanently at a high value, with noxious, toxic, and lesion effects in CNS as well as in other organism structures.

In the brain, these effects are characteristics and manifest by:

- losing selective cell in hippocampus [38];

- losing glucocorticoid receptors [37], along with growing older and older;

- reducing cerebral neurotransmitter synthesis, while affecting memory and concentration capacity [40]; and

- disturbing the neurotransmitters' metabolism, by involving modifications of dopamine and serotonin, with the onset of anxiety and depression [4].

At the organism level they trigger:

- cardio-vascular conditions, high blood pressure, cholesterol and triglyceride increased levels; 
- diabetes mellitus, high glycaemia and insulin-resistance;

- obesity by increased appetite, reduction of fat oxidation (degradation) and growth of deposits;

- osteoporosis via acceleration of bone mass loss;

- atrophy of muscles via loss of muscle mass;

- viral, bacterial, and fungal infections via loss of immune capacity and of immune cells' number and activity.

Thus, (mal)adaptation diseases and the stress-dependent pathology leave a mark on the organism as consequence of an increased BV.

\section{Etiopathogenic, entropic cascade (tetrad): distress $\leftrightarrow$ wear-and-tear $\leftrightarrow$ ageing $\leftrightarrow$ Poly-pathology}

The human being acts as a bio-psycho-social entity, connected to a complex environment (natural and artificial, built by civilisation), in on-going movement and accelerated change (the "revolutions", of industrialisation, urbanisation, transports, information reaching their peak in globalisation). Therefore, the individual's health and disease are determined by phenomena of multiple causes and factors [34].

A holistic and dynamic evaluation of the organism-environment interaction and sanogenesis-pathogenesis, from the bio-medical concepts described herein point of view (mainly distress/vulnerability), lay the basis of a new paradigm in public health and medicine, namely the etiopathogenic tetrad-cascade: distress $\leftrightarrow$ wear-and-tear $\leftrightarrow$ ageing $\leftrightarrow$ poly-pathology $[31 ; 32]$.

\subsection{Components of the tetrad: characterisation, structure, and dynamics}

A general definition of the tetrad involves [31]:

(1) - distress (acute-chronic; due to the environment-society-psycho-social; metabolic-oxidative-biological) [27];

(2) - weariness (stage 3 of SGA), wear-and-tear [29], deterioration, the triple action of oxidative stress (the increase of free radicals attack $\oplus$ the decrease of anti-oxidising defence $\oplus$ progressive accumulation of sub-cellular waste) $[6 ; 29]$;

(3) - ageing (negligible, gradual, accelerated or fast; normal and pathological) [18];

(4) - disease and poly-pathology (genetic-acquired; acute-chronic; free radicals diseases/oxidative stress/inflammatory/degenerative; stress-dependent pathology; somatic diseases; age-related diseases; poly-pathology of the elderly) $[8 ; 15]$.

The four tetrad components create an etiopathogenic entropic cascade (Fig.). Their common fundamental traits are given in the Table. By successive accumulations, global dynamics, the cascade over time "functioning" in ontogenesis, they determine health ruin with onset of diseases and finally the system destruction (the individual's death). 


\section{Health of the individual}

Progressive levels of

destructive cascade
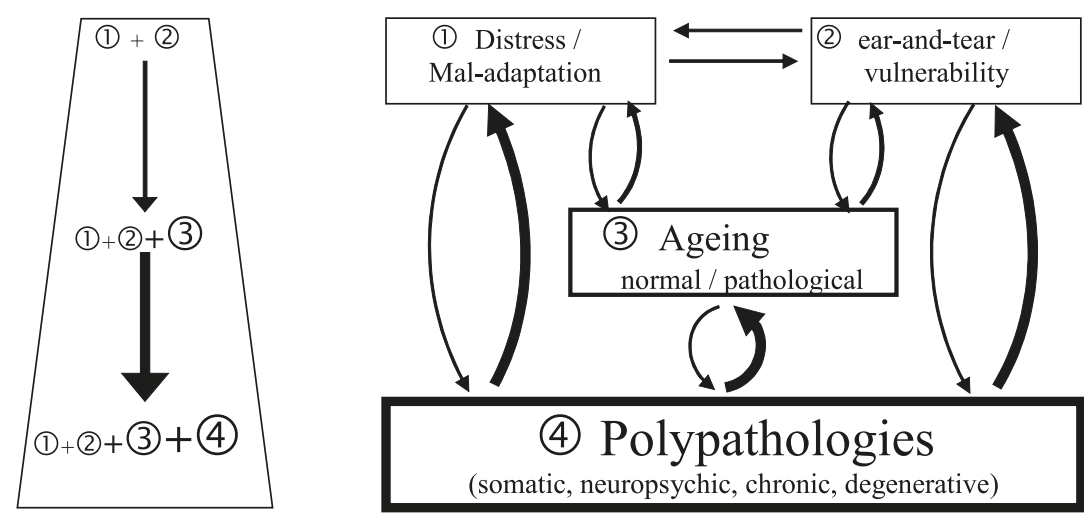
$[35 ; 36]$

Fig. The distress dynamic structure $\leftrightarrow$ wear-and-tear $\leftrightarrow$ ageing $\leftrightarrow$ poly-pathology cascade

Table. Etiopathogenic cascade fundamental features:

distress $\leftrightarrow$ wear-and-tear $\leftrightarrow$ ageing $\leftrightarrow$ poly-pathology $[35 ; 36]$

Amplifying interconnection among the four entities:

(1) Distress $\leftrightarrow$ (2)Wear-and-tear $\& \& \& \leftrightarrow$ (3) Ageing $\leftrightarrow$ (4) Poly-pathology

1. They are entropic processes: increase entropy, with disorganising the system

2. They have anti-homeostatic, anti-allostatic and anti-stability action

3. They trigger the progressive decrease of the adaptive capacity, resistance and vitality (structures-functions-energy-psycho-neuro-biological-metabolic information)

4. They increase the oxidative stress activity $\rightarrow$ increase damage caused by oxidative stress $\rightarrow$ Induce diseases of oxidative stress and

5. They trigger pro-inflammatory sub-clinical (silent) syndrome $\rightarrow$ inflammatory syndrome $\rightarrow$ generalisation (via blood) to organs

6. They disturb immunity: immune-related deficiencies, auto-immune and proliferative diseases

7. They become risk factors and etiopathogenic factors, they trigger and/or accelerate distress, deteriorations, pathological senescence (dementia) and diseases (poly-pathology)

8. Triggers $\rightarrow$ specific associated pathologies:

- distress $\rightarrow$ stress-dependent pathology, psychosomatic conditions,

- wear-and-tear $\rightarrow$ neurasthenia, chronic fatigue syndrome, dysmetabolic syndrome

- ageing $\rightarrow$ age-related conditions

- diseases, from acute to $\rightarrow$ chronic and degenerative ones

9. Continuous hetero- and/or auto-intensification via vicious circuits, pathological cascades and multiple, simultaneous associations 


\subsection{Fundamental mechanisms \\ of the cascade triggered/aggravated by distress}

Throughout ontogenesis, the etiopathogenic tetrad turns into a self-sustained cascade, which is aggravated by vicious pathological multiplication circuits. In their turn, each process acts onto the next by increasing vulnerability and diminishing adaptation.

The progredient unbalance caused by oxidative stress is a common link of the tetrad components; it increases by continuous multiplication from distress $\rightarrow$ wear-and-tear $\rightarrow$ ageing $\rightarrow$ to disease and poly-pathology and eventually reaches the maximum morbigenic disturbance by the four processes concomitance $[32 ; 33]$. To synthesise, the fundamental mechanisms of the cascade/tetrad of distress are represented by:

- allostatic load, overexposure to stress hormones over time, excessive, prolongedchronic hyperactivity, exhaustion of adaptation [38];

- increase of global vulnerability and progredient augmentation action of this fragility cascade;

- progressive multiplication of risks and dangers at multiple levels, such as metabolic biological, immune, endocrine, nervous, psychic, behavioural [7];

- progression of wear-and-tear, damage and deterioration, with the constantly growing final accumulation of macromolecular-sub-cellular waste and residues [29; 45];

- conditions of free radicals and oxidative stress, inflammatory-autoimmune-degenerative conditions [21];

- abnormal apoptosis and necrosis, with cellular loss and death, tissual and organ atrophy;

- genomic instability, dis-differentiation, immunodeficiency [9], cancers;

- morbidity, pathological ageing, poly-pathology, severe quality of life alteration, death.

\subsection{Etiopathogenic determination (causality) of the tetrad}

The etiopathogenic tetrad (cascade) is modulated by the four processes interaction means (should we take into account intensity, period of actions and their consequences):

- stress and GAS [41;43];

- A, B, C, and D personality types;

- hypothalamus-hypophysis-suprarenal axis - HHS [7];

- vicious circuits distress $\rightarrow$ disease $\rightarrow$ distress.

The GAS stages related to homeo- and allostasis have opposed significance: stage I (alarm) and III (weariness, long-term stress) are critical, with a high degree of vulnerability whereas stage II (adaptation, resistance) provides stability to the system. In stages I and III, owing to their amplitude (intensity), excessive duration, exceeding the level of proadaptation, they trigger increased vulnerability and the onset of disease. As a rule, there is a stage-specific pathology. For stage I, it is represented by acute modifications, mental disorder, and somatic conditions. For stage III, it includes chronic deteriorations and affections, immune deficiencies (which induce infectious diseases or cancer), inflammatory 
and infectious pathology, cell death, atrophy and pathological ageing. The SGA stages are amplified (via pathology) or reduced (promoting sanogenesis) by means of functioning pairs: acute-chronic distress/eustress $\oplus$ conditions of highly stressful/lack of stress lifestyles $\oplus \mathrm{A}, \mathrm{C}, \mathrm{D} / \mathrm{B}$ personality types.

Acute stress $\oplus$ highly stressful lifestyles $\oplus A$ and D personality types generate together the hyperadrenergic state $[7 ; 8]$ with:

- mental pathology and specific behaviour: psychic reactions to severe stress and conditions of adaptation, phobic anxiety, anxiety, dissociative conditions (of conversion) or somatoform ones; and

- somatic pathology: cardiovascular diseases (arrhythmia, high blood pressure, ischemic cardiopathy, acute myocardial infarction) and cerebral-vascular conditions (ischaemic or haemorrhagic stroke).

Chronic stress $\oplus$ highly stressful lifestyles $\oplus \mathbf{C}$ personality type alter together the activity of the HHS axis (by increasing or decreasing its normal function).

Associates states, in a chronic or recurrent manner, with additional load of hyperactive stress $\rightarrow$ the excessive function of HHS axis $\rightarrow$ hypercortisolism $\rightarrow$ alteration of behaviour adjustment $\rightarrow$ modification of peripheral adaptation [8] are represented by:

- chronic stress, excessive physical exercise (performance athletics);

- menstrual syndrome, gravidity (last trimester);

- panic and anxiety disorders, obsessive-compulsive disorders, severe depression;

- chronic alcoholism, alcohol and narcotics withdrawal;

- hyperthyroidism, Cushing's syndrome, diabetes mellitus, dysmetabolic syndrome (X syndrome $=$ mild $\rightarrow$ moderate $\rightarrow$ severe: obesity, insulin resistance, dyslipidemia, high blood pressure);

- gastro-intestinal "functional" disorders.

States associates with weariness - hyperactivity of the stress system $\rightarrow$ HHS axis hypofunction $\rightarrow$ glucocorticoid deficiency $\rightarrow$ alteration of behaviour adjustment $\rightarrow$ modification of peripheral adaptation $[8]$ are:

- post-chronic stress;

- postpartum depression, menopausal depression;

- recurrent depression, chronic fatigue syndrome;

- nicotine withdrawal;

- hypothyroidism, cortico-suprarenal insufficiency, treatment of post-Cushing syndrome, post-glucocorticoid therapy;

- fibromyalgia, rheumatoid arthritis.

The vicious circuits distress $\rightarrow$ pathology $\rightarrow$ distress trigger, maintain, and aggravate diseases and increase the treatments efficiency in somatic conditions. Stress never acts alone but accompanied by lack of balance and the consequences they trigger.

Distress induces the psychopathological triad: distress ? $\oplus$ anxiety $\oplus$ depression, which turns into the tetrad distress $\oplus$ anxiety $\oplus$ depression $\oplus$ sleep disorders [10; 52]. The consequences of these two entities (triad and tetrad) are represented by the HHS axis and immunity alteration of which, in their turn, trigger and aggravate somatic diseases. 


\subsection{Diagnosis and assessment of cascade: harmfulness and intensity}

The complexity, the interactions, and the tetrad consequences can only be evaluated from a multivalent point of view and by means of multi-axial instruments. The four entities of the cascade should be investigated individually, on the whole, simultaneously, multiple and in dynamics. A global diagnosis is required (which the current stage of biomedical technology provides) and a holistic treatment (which can be possible by means of the currently admitted concepts and of the intensive development of etiopathogenic and orthomolecular therapies).

Distress is researched at the psycho-social and biological - oxidative stress level.

When assessing psychic, social, societal stress a multi-axis scale is used, WSP Wheatley Stress Profile [51], which measures via nine axes (life areas) the following: social habits (4 items), social kinds of stress (6 items), life events (5 items), sexual issues (6 items), sleep parameters (5 items), psychic state (6 items), old age - over 65-year-olds ( 4 items), for women, menstruation - menopause ( 7 items), stress and the cardiovascular system (2 items).

The diagnostic and quantification by means of the WSP instrument provides the following data:

- the stress level in various life area (the nine axes), graded in six intensities: irrelevant, mild, moderate, marked, severe, and extremely severe;

- total stress score, individualised for each aria and global for the patient; and

- the quantity of stress in a certain period of life.

The WSP scale characterises global stress' multiple valences in the tetrad-cascade at the following levels:

- psycho-social: axes 1,2, and 3;

- psychiatric: axes 5 and 6;

- psychosomatic: axes 4, 8, and 9;

- ageing: axis No 7, directly, and the other eight axis, indirectly.

The stress evaluation at the biological level - oxidative stress, a phenomenon involved in the etiopathogenesis of over 100 diseases in humans and animals, is conducted in two opposite directions:

- measuring the aggressing factors - free radicals (mainly oxygen and nitrogen reactive species);

- dimensioning organism anti-oxidising defence; and

- determining the ratio (of the oxidative stress): pro- / anti-oxidants.

The OSP - Oxidative Stress Profile [12;13] measures the most widespread and noxious free radicals for the cellular-sub-cellular structures: oxygen singlet, superoxide, hydroxyl, peroxyl, hydrogen peroxide, nitric oxide.

TAS - Total Antioxidant Status $[12 ; 13]$ quantifies the free anti-radicals defence levels (in serum or plasma): superoxide dismutase, glutathione peroxidase, glutathione reductase, iron-TIBC (total iron-binding capacity), transferrin, ferritin, albumin, bilirubin, and uric acid.

TMA - Tissue Mineral Analysis (the mineralogram, hair analysis test) determines 39 macro-, oligo-, and microelements (18 having an essential role, 15 are noxious if in 
large quantities, six are extremely noxious), stress diagnosis (acute-chronic, neuro-endocrine, oxidative-metabolic, the three SGA stages), and the anti-stress adaptation (vegetative nervous system, endocrine, energetic-oxidative metabolism) [50].

The wear-and-tear-senescence diagnosis should highlight early on and in due therapeutic time the disorders on the verge of onset, which accelerate ageing and onset of pathology. It stands as a necessary desideratum in health promotion and disease prevention.

The identification of lifestyles, most often anti-sanogenetical ones, is continued with the general clinical examination and haematological and biochemical standard determinations. In addition, the imagistic technology - PET/CT (positron emission tomography/ computed tomography) contributes to a fast and accurate diagnosis of the chronic-degenerative inflammatory pathology and of the proliferative (cancerous) one. Determination and analysis of pro-inflammation, chronic inflammation, and tumour markers indices completes the patient's global evaluation.

In normal senescence, pathological ageing, and geriatric neuropsychological treatments, global investigation needs to be extended to the psychopathological level with other multidimensional assessment instruments [5]. To this purpose, the application of a pair of a psychometric-medical scale is highly recommended. For example, SCAG Sandoz Clinical Assessment-Geriatric Scale [44] - a hetero evaluation scale, with seven degrees of symptoms intensity, can be associated to SASG - Self-Assessment Scale-Geriatric [53] - a auto-evaluation scale with seven grades of symptoms frequency. The SCAG and SASG scales consist of 19 items (18 specific symptoms and one global item), grouped in five structural factors (axes): cognitive dysfunctions, interpersonal relations, affective disorders, apathy, and somatic dysfunctions.

In this algorithm, the diagnosis disease-poly-pathology is fast, precocious, and with high therapeutic chances.

In conclusion, the diagnosis of each entity of the tetrad, correlated with the cascade global evaluation as noxiousness and intensity, give a complete picture of the health $(+) /(-)$ - lack of health of the individual, defined as an active and useful bio-psychosocial being. In addition, therapeutic interventions can be conducted in real time and reversibility and recovery are significant.

\section{Conclusions}

Throughout ontogenesis, the human being navigates from the good health of young age to old age and pathology. Human vulnerability is a key factor in triggering, reception, propagation, aggravation, and multiplication of diseases. The etiopathogenic entropic cascade (tetrad): distress $\leftrightarrow$ wear-and-tear $\leftrightarrow$ ageing $\leftrightarrow$ poly-pathology develops slowly, throughout the individual's ontogenesis to which it sets limits and shortens.

\section{References}

1. Ativie F. The role of endocannabinoid system in neuron-glial communicationin in the ageing and diseased brain. PhD Thesis at Rheinischen Friedrich-Wilhelms-Universität Bonn. Bonn, 2017.

2. Auer R. N., Benveniste H. Hypoxia and related conditions, In: D. I. Graham, P.L.Lantos (Eds). Greenfield's Neuropathology, $6^{\text {th }}$ ed. London, Arnold, 1997, pp. 263-314.

3. Benveniste H., Drejer J., Schousboe A., Diemer N.H. Elevation of the extracellular concentrations of glutamate and aspartate în rat hippocampus during transient cerebral ischemia monitored by intracerebral microdialysis. J. Neurochem., 1984, vol. 43, pp. 1369-1374. 
4. Bikov Y. V., Bekker R. A., Reznikov M. K. Depression and Resistance. Practical Guide. Moscow, Infra-M, 2013. (In Russian)

5. Burns A., Lawlor B., Craig S. (Eds.). Assessment Scales in Old Age Psychiatry. London, Martin Dunitz, 1999.

6. Carr J.A. Shortwave infrared imaging and its translation to clinically-relevant designs. $\mathrm{PhD}$ Thesis at Massachusetts Institute of Technology, Cambridge, MA, 2018.

7. Chrousos G. P., McCarty R., Pacak K. et al. (Eds.). Stress-Basic Mechanisms and Clinical Implications. Ann. New York Acad. Sci., 1995, vol. 771, pp. 535-550.

8. Cooper C. (Ed.). Handbook of Stress, Medicine, and Health. Boca Raton, CRC Press, 1996.

9. Cooper E. L. Stress, Immunity, and Aging. New York, M. Dekker, 1984.

10. Cornuțiu, G. (Ed.). Al 2-lea Congres Național de Psihiatrie „Tulburările nevrotice în actuala dinamică a factorilor de stres". Volum lucrări. Capitolul IV.Vulnerabilitate, Oradea, RO. Ed. Imprimeriei de Vest, 2003, pp. 213-291.

11. Cornuțiu G. Breviar de psihiatrie. Oradea, RO. Ed. Imprimeriei de Vest, 2008.

12. Cutler R. G., Rodriguez H. (Eds.). Critical Reviews of Oxidative Stress and Aging. Advances in Basic Science, Diagnostics and Intervention, vol. 1. River Edge, World Scientific, 2003.

13. Cutler R. G., Rodriguez H. (Eds.). Critical Reviews of Oxidative Stress and Aging. Advances in Basic Science, Diagnostics and Intervention, vol. 2. River Edge, World Scientific, 2003.

14. Dănăilă L., Popescu I., Păiş V., Riga D., Riga S., Păiş E. Apoptosis, paraptosis, necrosis, and cell regeneration in posttraumatic cerebral arteries. Chirurgia (Buc.), 2013, vol. 108, pp. 319-324.

15. Derevenco P., Anghel I., Băban A. Stresul în sănătate și boală. De la teorie la practică. Cluj-Napoca, Ed. Dacia, 1992.

16. Derevenco P. Romanian scientific progress in international stress research and stress-aging medicine. Fiziologia-Physiology, 2006, vol. 16, pp. 9-14.

17. Fahy G. M., West M.D., Coles L.S., Harris S. B. (Eds.). The Future of Aging. Pathways to Human Life Extension. Dordrecht, Springer, 2010.

18. Finch C.E. Variations in senescence and longevity include the possibility of negligible senescence. J. Gerontol. Biol. Sci., 1998, vol. 53A, pp. 235-239.

19. Garcia J.H. Morphology of global cerebral ischemia. Crit. Care Med., 1989, vol. 16, pp. 979-987.

20. Garcia J.H., Anderson M.L. Circulatory disorders and their effects on the brain, In: R.L.Davis, D. M. Robertson (Eds.). Textbook of Neuropathology, $2^{\text {nd }}$ ed. Baltimore, Williams \& Wilkins, 1991, pp. 621-718.

21. Harman D. Free radical theory of aging and disease. Fiziologia-Physiology, 2004, vol. 14, pp. 4-6.

22. Kerr J.F. R., Wyllie A.H., Currie A.R. Apoptosis: a basic biological phenomenon with wide-ranging implications in tissue kinetics. Br. J. Cancer., 1972, vol. 26, pp. 239-257.

23. Riegle G.D. Chronic stress effects on adrenocortical responsiveness in young and aged rats. Neuroendocrinology, 1973, vol. 11, pp. 1-10.

24. Riga S. Studii asupra Acizilor Nucleici din Sistemul Nervos Central în Procesele de Senescență. București, Teză de Doctorat la Institutul de Medicină şi Farmacie. București, 1976.

25. Riga D., Riga S. Mărirea vitalităţii creierului, factor în promovarea stării de sănătate mintală. Revista Sanitară Militară, 1979, vol. 82, pp. 421-431.

26. Riga D., Riga S., Schneider F. Regenerative medicine: Antagonic-Stress" therapy in distress and aging. I. Preclinical synthesis - 2003, In: A. D. N. J. de Grey (Ed.), Strategies for Engineered Negligible Senescence. Why Genuine Control of Aging May Be Foreseeable. Ann. New York Acad. Sci., 2004, vol. 1019, pp. 396-400.

27. Riga S., Riga D. (Eds.). Stresul şi societatea modernă. Revista Română de Sănătate Mintală, 2004, vol. 11, pp. 1-62.

28. Riga D., Riga S., Schneider F. Vulnerabilitate, stres şi îmbătrânire: dimensiunea antropologică a stresului în senescență. Revista Română de Sănătate Mintală, 2004, vol. 11, pp. 35-44.

29. Riga D., Riga S., Hălălău F., Schneider F. Lipofuscin and ceroid pigments - markers of normal and pathological brain aging, In: R. Klatz, R. Goldman (Eds), Anti-Aging Therapeutics, vol. 8. Chicago, American Academy of Anti-Aging Medicine, 2006, pp. 213-222.

30. Riga D., Riga S., Hălălău F., Schneider F. Neurono-glial mechanisms in brain protection, aging deceleration and neuro-psycho-longevity, In: R. Klatz, R. Goldman (Eds.), Anti-Aging Therapeutics, vol. 8. Chicago, American Academy of Anti-Aging Medicine, 2006, pp. 223-235.

31. Riga D., Riga S. O nouă paradigmă în medicină şi psihiatrie: tetrada disstres $\rightarrow$ uzură $\rightarrow$ îmbătrânire $\rightarrow$ polipatologie, In: G. Cornuțiu, D. Marinescu (Eds.), Orientări şi perspective în gândirea psihiatrică românească actuală, Vol. 1. Oradea, Ed. Universității din Oradea, 2007, pp. 31-75. 
32. Riga D., Riga S. Medicina anti-îmbătrânire şi ştiințele longevităţii. Bucureşti, Ed. Cartea Universitară (Ars Academica), 2007.

33. Riga S., Riga D. Stresologie, adaptologie şi sănătate mintală. Bucureşti, Ed. Cartea Universitară (Ars Academica), 2008.

34. Riga S., Riga D., Mihăilescu A., Motoc D., Moş L., Schneider F. Longevity health sciences and mental health as future medicine, In: R.M. Tanguay (Ed.), Aging, Cancer, and Age-Related Diseases. Common Mechanisms? Ann. New York Acad. Sci., 2010, vol. 1197, pp. 184-187.

35. Riga D., Riga S. Capitol 6. Medicina stresului - necesitate a prezentului, In: J. Vincze (Ed.), Biofizică Medicală (Medical Biophysics), Biophysics. Budapest, Ed. NDP, 2011, vol. 38, pp. 141-174.

36. Riga D., Riga S., Motoc D., Geacăr S., Ionescu T. Ch. 17. Health-longevity medicine in the global world, In: J. Maddock (Ed.), Public Health. Methodology, Environmental and Systemic Issues. Rijeka, Croatia and Shanghai, China, InTech - Open Access Publ, 2012, pp. 347-366.

37. Sapolsky R. M., Krey L. C., McEwen B.S. Corticosterone receptors decline in a site-specific manner in the aged rat brain. Brain Res., 1983, vol. 289, pp. 235-240.

38. Sapolsky R.M., Krey L.C., McEwen B.S. Prolonged glucocorticoid exposure reduced hippocampal neuron number: implication for aging. J. Neurosci., 1985, vol. 5, pp. 1222-1227.

39. Sapolsky R. M., Krey L. C., McEwen B. S. The neuroendocrinology of stress and aging: the glucocorticoid cascade hypothesis. Endocr. Rev., 1986, vol. 7, pp. 284-301.

40. Sapolsky R. M., Packan D., Vale W. Glucocorticoid toxicity in the hippocampus: in vitro demonstration. Brain Res., 1988, vol. 453, pp. 367-371.

41. Selye H. The general adaptation syndrome and the diseases of adaptation. J.Clin. Endocrinol., 1946, vol. 6, pp. 117-230.

42. Selye H. Stress and aging. J. Am. Geriatr. Soc., 1970, vol. 18, pp. 669-680.

43. Selye H. The evolution of the stress concept. American Scientist, 1973, vol. 61, pp. 692-699.

44. Shader R.I., Harmatz J.S., Salzman C. A new scale for clinical assessment in geriatric populations: Sandoz Clinical Assessment-Geriatric (SCAG). J. Am. Geriatr. Soc., 1974, vol. 22, pp. 107-113.

45. Sigurdsson E. M., Calero M., Gasset M. (Eds.). Amyloid Proteins. Methods and Protocols. $3^{\text {rd }}$ ed. New York, Springer-Humana Press, 2018.

46. Sloper J.J., Johnson P., Powell T.P.S. Selective degeneration of inter-neurons in the motor cortex of infant monkeys following controlled hypoxia: a posible cause of epilepsy. Brain Res., 1980, vol. 198, pp. 204-209.

47. Tang F., Phillips J. G. Some age-related changes in pituitary-adrenal function in the male laboratory rat. J. Gerontol., 1978, vol. 33, pp. 377-382.

48. Tatu C., Schneider F., Tatu F. R., Puşcaşiu D., Siska I., Brestoviceanu D. Molecular chaperones and protein misfolding in disease. Fiziologia-Physiology, 2000, vol. 10, pp. 3-9.

49. Wallace D. C., Shoffner J. M., Trounce I., Brown M. D., Ballinger S. W., Corral-Debrinski M., Horton T., Jun A.S., Lott M. T. Mitochondrial DNA mutations in human degenerative diseases and aging. Biochimica et Biophysica Acta, 1995, vol. 1271, pp. 141-151.

50. Watts D. L. Trace Elements and other Essential Nutrients. Clinical Applications of Tissue Mineral Analysis. Dallas, Trace Elements, 1995.

51. Wheatley D. The Wheatley stress profile. Stress Med., 1993, vol. 9, pp. 5-9.

52. Wheatley D. Stress, anxiety and depression. Stress Med., 1997, vol. 13, pp. 173-177.

53. Yesavage J.A., Adey M., Werner P.D. Development of a geriatric behavioural self-assessment scale. J. Am. Geriatr. Soc., 1981, vol. 29, pp. 285-288.

54. von Zglinicki, T. Telomeric damage in aging, In: T.von Zglinicki (Ed.), Aging at the Molecular Level. Dordrecht, Kluwer, 2003, pp. 121-129.

Received: April 24, 2019

Accepted: July 17, 2019

Authors' information:

Sorin Riga - Professor, MD, PhD; d_s_riga@yahoo.com

Magdalena Budisteanu - M.D., PhD; magda_efrim@yahoo.com

Vitalie V.Scripnic — Professor, D. Habil (Biol.), PhD (Biophysics), M. D.; scripnicv@yahoo.com

Bogdan Budisteanu - Dr.; bbudisteanu@yahoo.com

Vlad Dionisie - Dr.; vlad.dionisie@gmail.com 